\title{
Nove mogućnosti liječenja „suhe” senilne makularne degeneracije
}

\section{Novel possibilities in treatment of dry age-related macular degeneration}

\author{
Tea Čaljkušić-Mance ${ }^{1 *}$, Zvjezdana Alpeza-Dunato ${ }^{1}$, Tamara Mišljenović-Vučerić ${ }^{1}$, \\ Renata Gržetić-Lenac ${ }^{1}$, Ivan Brumini²
}

\begin{abstract}
Sažetak: Senilna makularna degeneracija (engl. age-related macular degeneration; AMD) jedan je od najvažnijih uzroka gubitka centralnog vida kod starije populacije. Dijelimo je na „vlažnu" i "suhu” formu, ovisno o prisutnosti koroidne neovaskularizacije (engl. choroidal neovascularization; CNV). Do sada nijedna terapija nije potvrđena i odobrena za liječenje geografske atrofije (engl. geographic atrophy; GA), najtežeg oblika "suhog” AMD-a, jer nije bilo moguće popraviti oštećenja retinalnog pigmentnog epitela (engl. retinal pigment epithelium; RPE) i fotoreceptora. Liječenje se svodilo na pokušaje zaustavljanja progresije oboljenja i širenja geografske atrofije. Namjera ovog članka je prikazati podatke novijih dovršenih i tekućih kliničkih ispitivanja s naglaskom na mjesto djelovanja potencijalnih lijekova. Danas su nam dostupne brojne nove dijagnostičke metode koje nam omogućavaju bolje praćenje morfoloških promjena mrežnice, RPE-a i žilnice, kao i širenja područja atrofije. Oksidativni stres, kronična upala, insuficijentni koroidalni protok krvi te depoziti lipofuscina za koje se pretpostavlja da bi imali važniju ulogu u razvoju bolesti predstavljaju potencijalne mete za djelovanje lijekova. Velik je broj tekućih studija koje istražuju moguća rješenja, kao što su protuupalni i neuroprotektivni lijekovi te matične stanice, dok će samo neki od lijekova biti dostupni na tržištu i pružiti nadu pacijentima za očuvanje centralnog vida, pa ih je potrebno dugoročno pratiti. Uključiti treba i tretman ispodpražnim i mikropulsnim laserom koji je kod nekih oboljenja mrežnice pokazao određene rezultate u revitalizaciji tkiva, a koji koristimo i na našoj Klinici, te su prvi kratkoročni rezultati skromni ali ohrabrujući i zahtijevaju daljnje tretmane i praćenje.
\end{abstract}

Ključne riječi: geografska atrofija; makularna degeneracija; matične stanice; neuroprotektivni lijekovi; protuupalni lijekovi; retinalni pigmentni epitel

\begin{abstract}
Age-related macular degeneration (AMD) is one of the most important cause of central vision lost in elderly. AMD is "wet" or "dry", depending on choroidal neovascularization (CNV) presence. Currently, no treatment iz approved for geographic atrophy (GA), late form of "dry" AMD because of imposibillity to restore retinal pigment epithelium (RPE) and photoreceptors. So, all earlier treatment only tried to slow down disease and spreading of GA. This review focuses on current data about potential targets for therapies evaluated in novel clinical trials. Novel diagnostic tools are available today for better monitoring of morfological changes in retina, RPE and choroid and spreading of atrophy zone. Several pathways, including oxidative stress, deposits of lipofuscin, chronic inflammation andchoroidal blood flow insufficiency, seem to play an important role in the pathogenesis of "dry" AMD and represent possible targets for new therapies. A great number of treatment for GA such as antiinflammatory agents, neuroprotective agents and stem cells are under investigation with promising results in preliminary study, and only few will enter the market. Besides them we need to mention subtreshold and micropulse laser treatment with ability to revitalize tissue. We, also, used them on our Eye clinic with "short-term" follow-up and modest but encouraging results, so we need other studies with "long-term" follow-up.
\end{abstract}

Key words: anti-inflammatory agents; geographic atrophy; macular degeneration; neuroprotective agents; retinal pigment epithelium; stem cells

\author{
${ }^{1}$ Klinika za oftalmologiju, Klinički bolnički \\ centar Rijeka, Rijeka \\ ${ }^{2}$ Katedra za anatomiju i fiziologiju, \\ Zdravstveno veleučilište Zagreb, Zagreb
}




\section{UVOD}

Senilna makularna degeneracija (engl. age-related macular degeneration; AMD) jedan je od najvažnijih uzroka gubitka centralnog vida kod starije populacije razvijenih zemalja'. Degenerativna bolest centralnog dijela mrežnice multifaktorijalne je etiologije s tim da najvažniju ulogu imaju genetski faktori i utjecaj okoliša ${ }^{2}$. Dijelimo je na „vlažnu”, neovaskularnu i „suhu” formu, ovisno o prisutnosti koroidne neovaskularizacije (engl.

Geografska atrofija (engl. geographic atrophy; GA), terminalna forma "suhe” senilne makularne degeneracije (engl. age-related macular degeneration; AMD), progresivna je bolest i za sada nema odobrenog lijeka. U tijeku je više studija s ciljem pronalaženja učinkovite terapije za sprječavanje povećanja područja atrofije, izbjegavanje razvoja teže forme bolesti te očuvanja vidne funkcije. čenje GA-a, najtežeg oblika „suhog” AMD-a, jer nije bilo moguće popraviti oštećenja RPE-a i fotoreceptora. Liječenje se svodilo na pokušaje zaustavljanja progresije oboljenja i širenja geografske atrofije.

Ovaj pregled usredotočen je na najnovije mogućnosti liječenja „suhog” AMD-a vezano uz dovršene i tekuće kliničke studije ${ }^{10-12}$.

\section{DEFINICIJA}

Geografska atrofija definirana je kao oštro ograničeno okruglo ili ovalno područje hipopigmentacije ili vidljivog nedostatka RPE-a, gdje su koridalne krvne žile vidljivije nego u okolnom području, a koje u promjeru obuhvaća najmanje 175 mikrometara (slika 1$)^{5}$. $U$ ovom času nema internacionalnog konsenzusa minimalnog limita dijametra za dijagnozu geografske atrofije, pa neke studije, npr. CAPT (engl. Complications of Age-Related Macular Degeneration Prevention Trial) i AREDS2 (engl. Age-Related Eye Disease Study) navode kao minimum 250 odnosno 433 mikrometra ${ }^{12}$. Dodatno, prilikom određivanja težine stadija bolesti prema AREDS klasifikaciji, za pacijenta se smatra da ima uznapredovalu formu AMD-a samo ako GA uključuje centar makule odnosno foveu centralis ${ }^{13}$. U klasifikacijskom sistemu Beckmanove inicijative za makularna istraživanja prisutnost bilo kakvog GA-a, bez obzira na lokaciju, predstavlja dokaz uznapredovalog oblika bolesti ${ }^{14}$. Ako se na jednom oku paralelno pojave GA i CNV, smatra se da se radi o neovaskularnom obliku bolesti ${ }^{15}$.

\section{EPIDEMIOLOGIJA I FAKTORI RIZIKA}

Globalna prevalencija GA-a je 0,66 \% u svim dobnim skupinama, ali iznosi 0,34 \% između 65. i 74. godine, $1,3 \%$ između 75 . i 84 . godine i $4,4 \%$ kod ljudi preko 85 godina. Povećava se na $22 \%$ nakon 90 godina života ${ }^{16}$. Recentna metaanaliza zasnovana na podacima iz Sjedinjenih Američkih Država (engl. United States of America, USA) pokazuje da incidencija GA-a i neovaskularnog AMD-a (engl. neovascular age-related macular degeneration; nAMD) iznosi 1,9 i 1,8 na 1000 Amerikanaca, bijelaca, starijih od 50 godina. Prevalencija za obje forme AMD-a je usporedna kroz sve dobne skupine ${ }^{17}$. 
Za osobe s blagim ili intermedijarnim AMD-om 15-godišnja kumulativna incidencija nAMD-a približno je $2.0 \%$, a za progresiju u čisti GA otprilike $1,3 \%^{18}$. Za GA, kao i sve ostale forme AMD-a, najvažniji faktori rizika su dob, genetska podloga i pušenje ${ }^{16,19}$. Prema AREDS studiji, GA je također povezan s većim indeksom tjelesne mase (engl. body mass index; BMI), uzimanjem blokatora kalcijevih kanala i beta blokera, ne uzimanjem hormonskih nadomjestaka (žene), svjetlijom bojom šarenice i nižim obrazovanjem ${ }^{17,18,20,21}$. U Rotterdam i Beaver Dam Eye Study serumski HDL (engl. high-density lipoprotein) kolesterol je direktno povezan s GA-om, dok veza nije nađena u studiji Blue Mountains Eye Study22. $U$ istoj studiji dijabetes i omjer totalni/HDL kolesterol povezan je $s$ povećanim rizikom od GA-a. Kako sustav komplementa ima važnu ulogu u ovom oboljenju, komplement faktor $\mathrm{H}$ (engl. complement factor $\mathrm{H}$; $\mathrm{CFH})$ gen lociran na kromosomu $1 \mathrm{q} 32$ i druge komponente komplementa, kao CFB, CFI, C2 i C3 uključeni su u razvoj obje forme AMD-a ${ }^{23-25}$.

\section{PATOLOGIJA}

Termin „suhi” AMD uobičajeno pokriva širok spektar promjena očne pozadine koje uključuju pojavu druza, pregrupacije pigmenta i pojavu „,krpica" atrofije mrežnice ${ }^{14}$.

Prema AREDS studiji prijelomna točka koja vodi do GA-a je napredovanje velikih druza do hiperpigmentacije, a nakon toga postepenom regresijom druza, hipopigmentacijom i neizbježnom smrću stanica RPE-a, što je praćeno razvojem atrofije pojedinih područja retine poglavito u makuli i atrofije podležećeg koriokapilarisa. Razvoj promjena može trajati duže od šest godina ${ }^{26-28}$. Inicijalno pojavljivanje GA-a uobičajeno je nakon pet do šest godina postojanja velikih ili konfluentnih druza (> $125 \mu \mathrm{m}$ ) i hiperpigmentacije, dok u kombinaciji konfluentnih druza i hipopigmentacije taj period iznosi dvije godine i šest mjeseci ${ }^{10}$. Prisutnost velikih konfluentnih druza signifikantan je rizični faktor za razvoj GA-a ${ }^{29}$. Druze su pronađene kod $100 \%$ pacijenata koji su kasnije razvili GA; druze $>125 \mu \mathrm{m}$, konfluentne druze i hiperpigmentacija bili su prisutni u $>90 \%$ očiju s GA-om, a druze > $250 \mu \mathrm{m}$ i hipopigmentacija kod > $80 \%$ očiju ${ }^{30}$. Veća prevalencija retikularnih pseudodru- za (engl. reticular pseudodrusen; RPD) zabilježena je kod pacijenata s GA-om u usporedbi s ranim i intermedijarnim AMD-om. Ujedno, prisutnost RPD-a predstavlja značajan čimbenik rizika za progresiju AMD-a ${ }^{31,32}$.

Većina histopatoloških studija ukazuje da su stanice RPE-a primarna meta za GA, te da je njihova smrt uzrok atrofije podležećeg koriokapilarisa ${ }^{33,34}$. Autofluorescentni pigmenti kao što je lipofuscin, koji se akumulira u RPE stanicama, pridonosi smanjenju stanične funkcije, degeneraciji i posljedičnom GA-u ${ }^{35}$. Pored RPE stanica koje su najjače zahvaćene promjenama, vanjski nuklearni sloj također je teško pogođen putem disfunkcije i smrti fotoreceptora, s tim da je vjerojatna prvenstvena zahvaćenost štapića ${ }^{36,37}$. Mehanizam stanične smrti kod RPE-a najbolje je proučen u graničnoj zoni, u kojoj lipofuscin može zauzeti $30 \%$ stanice RPE-a te interferirati sa staničnim metabolizmom uzrokujući staničnu smrt. Ti mehanizmi uključuju upalu i oksidativni stres ${ }^{38-41}$.

\section{DIJAGNOSTIKA I PRAĆENJE}

GA za početak razlikujemo od ostalih oblika AMD-a indirektnom biomikroskopijom i fundus fotografijom u boji (engl. color fundus photography; CFP) (slika 1$)^{10}$. Definicija GA-a zasniva se na kliničkom pregledu i histopatološkom nalazu koji pokazuje klinički vidljive zone atrofije koje karakterizira stanična smrt RPE-a, vanjske neurosenzorne mrežnice i koriokapilarisa.

Sve te morfološke promjene mrežnice, RPE-a i žilnice prikazuju se i prate osim CFP-om i ostalim modernim in vivo dijagnostičkim pretragama, kao što su fundus autofluorescencija (engl. fundus autofluorescence; FAF), optička koherentna tomografija (engl. optical coherence tomography; OCT) i novija optička koherentna tomografija angiografija (engl. optical coherence tomographyangiography; OCTA $)^{10,42,43}$.

\section{Fundus fotografija u boji (CFP)}

CFP ima ograničene mogućnosti otkrivanja i praćenja progresije atrofičnih zona. Tipično se prikazuje dobro ograničena ovalna zona atrofije RPE-a s oštro ograničenim rubovima i pojačanom vidljivošću koroidalnih krvnih žila te obično pošteđena fovea sve do terminalnog stadija (slika 1). 


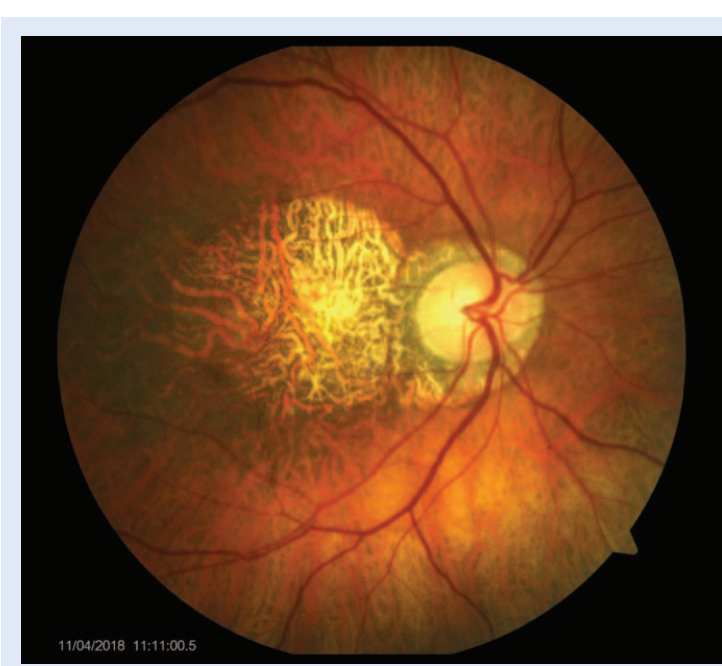

Slika 1. Geografska atrofija - fundus fotografija u boji

\section{Optička koherentna tomografija (OCT)}

OCT se trenutno sve više koristi u kliničkoj praksi kao standard za dijagnostiku i praćenje "suhog" AMD-a stoga što omogućava izvrsnu vizualizaciju, mjerenje i monitoring retinalnih slojeva, RPE-a, hiperreflektivnih fokusa (engl. hyperreflective foci;
HRF), područja s GA-om i druza ${ }^{44-47}$. OCT prikazuje svih 10 slojeva mrežnice u makuli te daje uvid i u neke promjene žilnice.

OCT prikazuje stanjenje hiperreflektivnog vanjskog sloja, što korespondira s atenuacijama RPE/ Bruch's kompleksa i dublju hiperrefleksivnost zbog gubitka vanjskih slojeva, uključujući fotoreceptore $^{48,49}$ (slika 2). Identificirane su promjene $u$ OCT snimci koje mogu pretkazati razvoj GA-a. Te promjene uključuju prisutnost HRF-a iznad područja druza, slijeganje unutarnjeg nuklearnog sloja (INL, engl. internal nuclear layer) i vanjskog pleksiformnog sloja (OPL, engl. outer plexiform layer) s razvojem hiporeflektivne, klinaste trake i pojačan signal transmisije ispod nivoa RPE-a. Ove anatomske promjene mogu biti korisne za otkrivanje pacijenata s tendencijom razvoja GA-a, koji su još u reverzibilnoj fazi te kao takvi pogodniji za intervenciju ${ }^{50-52}$. OCT prikaz također omogućuje bolje razumijevanje podležećih patoloških mehanizama u AMD-a i GA-a koji mogu ukazati na nove biomarkere povezane $s$ napredovanjem bolesti i inicirati nove ciljeve terapije u AMD- $a^{12}$.

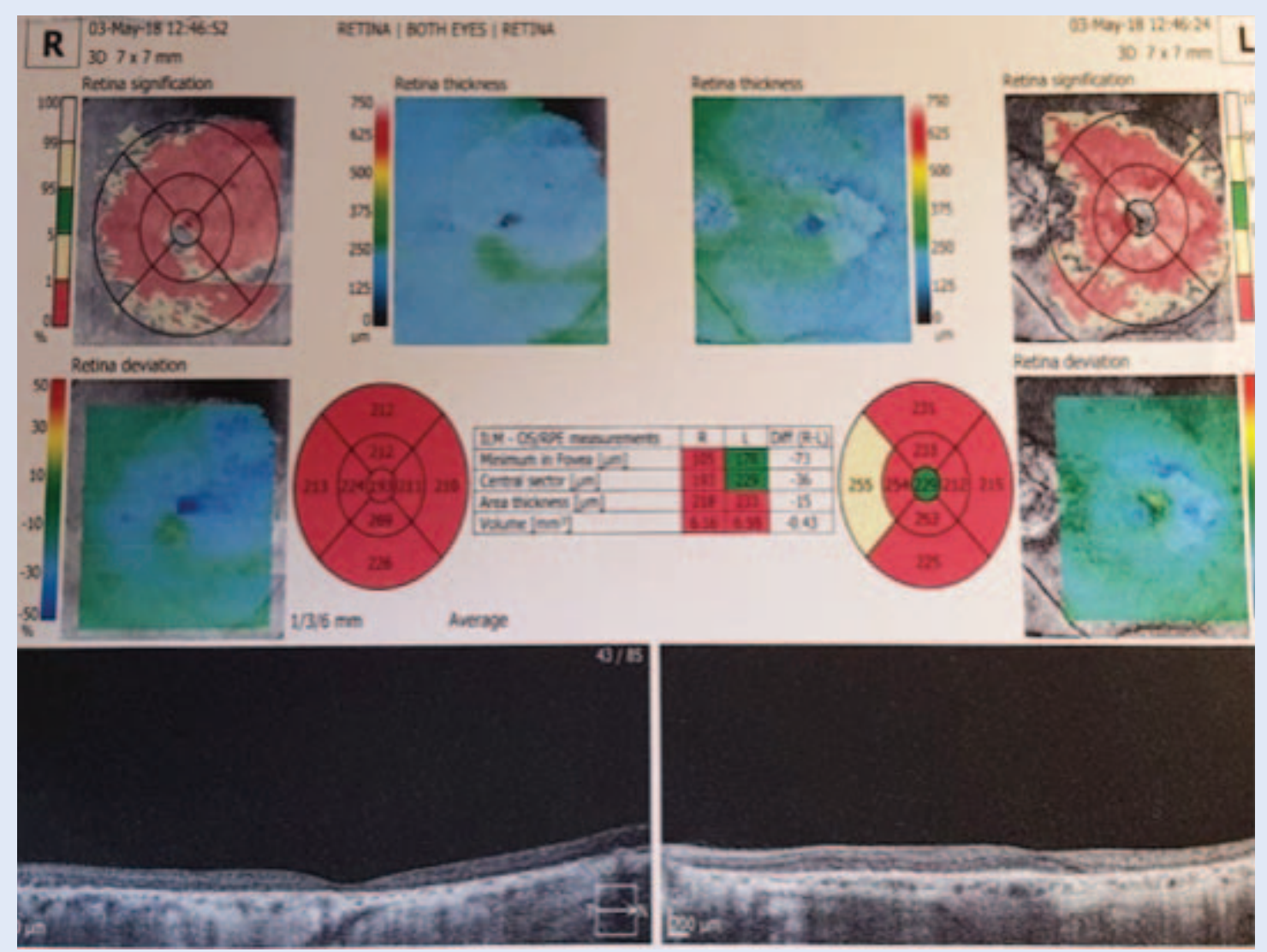

Slika 2. Optička koherentna tomografija (OCT, engl. optical coherence tomography) - prikaz geografske atrofije 


\section{Fundus autofluorescencija (FAF)}

FAF se trenutno smatra zlatnim standardom $\mathrm{u}$ praćenju progresije atrofičnih zona, ujedno pojedini autori sugeriraju da FAF može predvidjeti stopu progresije GA-a ${ }^{42,43}$. FAF predstavlja akumulaciju lipofuscina u lizosomima stanica RPE-a, poteklih uglavnom od degradacije vanjskog segmenta fotoreceptora. Povišen FAF znak je razvoja $G A-a^{43,53}$. FAF je povišen u graničnoj zoni oko zone atrofije, a intenzitet korelira s proširenjem zone atrofije i redukcijom retinalne osjetljivosti, što se može detektirati fundus perimetrijom (slika 3$)^{43,54}$

FAM-studijska grupa razvila je klasifikaciju za abnormalni FAF te razlikuje 5 primarnih fenotipova ovisno o prisutnosti povišene hiperautofluorescencije: 1) bez; 2) fokalna; 3) trakasta; 4) krpičasta; i 5) difuzna ${ }^{55}$. Poremećaji u FAF-u imaju puno veću povezanost s progresijom atrofije od bilo kojeg drugog faktora rizika spomenutog u ranijim studijama $^{56}$.

\section{Optička koherentna tomografija angiografija (OCTA)}

OCTA je relativno nova neinvazivna dijagnostička tehnika koja može prikazati promjene u koroidalnoj vaskularnoj mreži u ranoj, intermedijarnoj i kasnoj fazi "suhog” AMD-a ${ }^{57,58}$. Pokazalo se da u ranim fazama bolesti koroidalni sloj pokazuje dramatične alteracije $u$ sastavu $s$ prevladavanjem stromalnog tkiva nad vaskularnom mrežom $^{57}$. Premda je ova tehnika tek u razvoju, OCTA obećava jer pruža istovremenu informaciju o funkcionalnim i strukturnim promjenama te se očekuje daljnje usavršavanje tog korisnog dijagnostičkog alata.

\section{PREVENCIJA}

Posljednjih je godina izrazito pojačan interes za utjecaj prehrane na zdravlje. Mnoga istraživanja pokazala su da sastojci prehrane mogu smanjiti incidenciju određenih bolesti, među njima i AMD. AREDS studija pokazala je da AREDS formula (dnevna doza od $80 \mathrm{mg}$ cink-oksida, $2 \mathrm{mg}$ bakar-oksida, 15 mg $\beta$-karotena, 500 mg vitamina C i 400 IU vitamina E) značajno reducira rizik progresije AMD-a kod određene skupine pacijenata sa „suhim” AMD-om²1. Takav rezultat postignut je

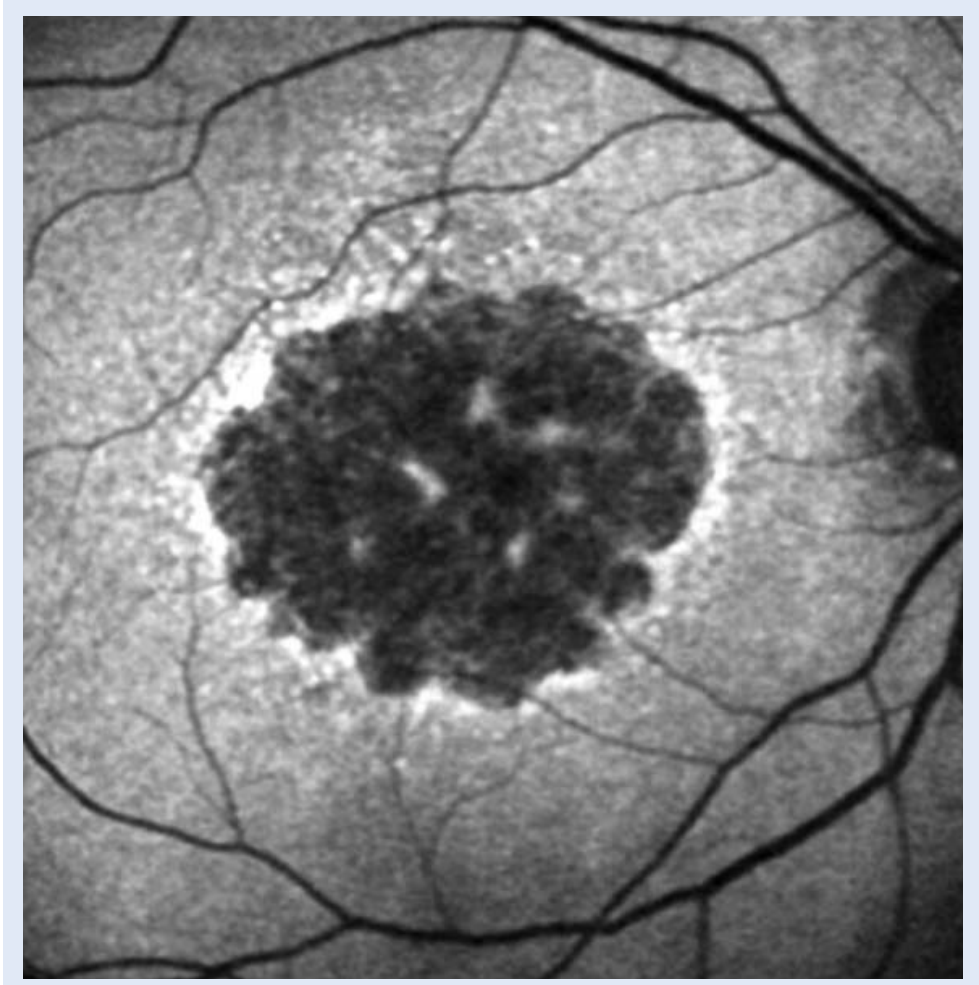

Slika 3. Fundus autofluorescencija

kod pacijenata koji su u studiju ušli u kasnijim fazama bolesti, točnije za kategorije 3 i 4, pa sve do uznapredovalih formi, (25\% u 5 godina), dok je efekt na pacijente u početnim fazama nepoznat ${ }^{21}$. Pored toga AREDS Report No8 zaključuje da pacijenti s necentralnim GA-om također imaju koristi od uzimanja antioksidanata i cinka ${ }^{13}$.

Otkad je ustanovljena povećana incidencija karcinoma pluća kod pušača, iduća studija AREDS2 pokazala je da uklanjanje $\beta$-karotena ili smanjenje doze cinka u formuli nema utjecaja na progresiju u kasni stadij AMD-a ${ }^{59,60}$. No, velika incidencija karcinoma pluća zabilježena je kod pacijenata koji su uzimali AREDS formulu u odnosu na one koji su uzimali AREDS2 formulu, poglavito kod prijašnjih pušača ${ }^{60}$.

Sadašnje novo područje istraživanja predstavlja veza između vitaminskih dodataka prehrani i genetskog profila. Zasniva se na dokazima koji pokazuju da genetski profil pacijenta može utjecati na korist od uzimanja vitaminskih dodataka prehrani ${ }^{61}$. Rezultati ovog specifičnog područja istraživanja bit će dostupni do kraja tekuće godine.

Zaključno, postoji opće mišljenje da AREDS i AREDS2 formula imaju povoljan efekt uglavnom 
zbog svog antioksidativnog djelovanja i da će kao takvi imati veliku ulogu u prevenciji progresije „suhog” AMD-a kroz duži vremenski period.

\section{LIJEČENJE - NOVIJI TERAPIJSKI PRISTUP}

Kao što je ranije navedeno, do danas nema odobrenog efektivnog liječenja za sprječavanje pojave i progresije „suhog“ AMD-a odnosno GA-a ${ }^{10,29}$. Premda je glavna meta koja potiče nastanak „suhog" AMD-a i GA-a i dalje nepoznata, više studija ispituje potencijalne strategije ovisno u putevima i mjestima nastanka bolesti i ciljevima terapije kao što su:

1. Toksični produkti vidnog ciklusa (modulatori vidnog ciklusa)

2. Upala, aktivacija sustava komplementa (protuupalni lijekovi, inhibitori komplementa)

3. Akumulacija beta-amiloida (anti-amiloid beta lijekovi)

4. Oksdativni stres (antioksidanti i neuroprotektivni lijekovi)

5. Atrofija koriokapilarisa (pojačivači koroidalne perfuzije)

6. Gubitak RPE-a i fotoreceptora (terapija matičnim stanicama, neurotrofini)

7. Akumulacija lipida (antilipidni lijekovi) ${ }^{10}$.

\section{Modulatori vidnog ciklusa i lipofuscin}

Razlog za upotrebu modulatora vidnog ciklusa u liječenju GA-a je dokumentirani fototoksični i proinflamatorni efekt akumulacije lipofuscina na mjestu RPE atrofije kod pacijenata s GA-om ${ }^{62}$.

ALK-001 je modificirana molekula vitamina A koja usporava formaciju lipofuscina i RPE apoptozu. Inicijalno je dizajnirana za liječenje Stargardtove bolesti. Faza 1 studije dizajnirana je da ispita sigurnost i farmakokinetiku oralnih kapsula ALK001 kod 40 zdravih volontera; još nemamo dostupne rezultate ${ }^{10,11}$.

Fenretinide (Sirion Therapeutics, Tampa, FI, USA) je sintetski retinoid koji kompetitivno sprječava porast retinola u RPE s modulacijom vidnog ciklusa. Faza II kliničkog ispitivanja (NCT00429936) pokazuje da 100 mg i 300 mg dnevno Fenretinida ne smanjuje stopu rasta GA-a, ali ga pacijenti dobro podnose ${ }^{63}$.

Emixustat (ACU-4489; Acucela, Seattle, WA, USA) je ne-retinoidni modulator vidnog ciklusa izome- raze RPE 65 koji sprječava konverziju all-trans-retinola u 11-cis-retinalin u RPE s minimalnom akumulacijom lipofuscina. Faza Ila ispitivanja (NCT01002950) pokazuje biološki efekt u pacijenata s GA-om ${ }^{64}$. Faza II/III studije (NCT01802866) je dovršena, ali nije pokazala zadovoljavajuće rezultate (liječenje u dozama od $2.5 \mathrm{mg}, 5.0 \mathrm{mg}$ i 10 mg dnevno nije u 24-mjesečnom ispitivanju pokazalo bitno bolje rezultate od placeba ${ }^{65}$.

\section{Protuupalni lijekovi}

Postojanje kronične upale smatra se ključnim za AMD patogenezu ${ }^{66,67}$.

Trenutno se istražuju kortikosteroidi zbog svog antiangiogenog i protuupalnog efekta.

Fluocinolone acetonide (Iluvien"; Alimera Sciences, Alpharetta, GA, USA) je sporo otpuštajući oblik fluokinolon acetonida odobren za tretman dijabetičkog makularnog edema (DME, engl. diabetic macular edema) koji bi mogao usporiti progresiju GA-a. U Fazu II studije (NCT00695318) uključeno je 40 pacijenata s obostranim GA-om ${ }^{67}$. Studija je dovršena, ali rezultati još nisu dostupni. Histopatološka identifikacija različitih kompleksa komplementa kod pacijenata s GA-om i prisutnost genskih varijacija za kodiranje proteina komplementa razjašnjavaju neke od novijih terapeutskih strategija ${ }^{68,69}$. Premda se više inhibitora sustava komplementa ispitivalo za liječenje GA-a, nijedan još nije odobren kao uspješan.

POT-4 (Potentia Pharmaceuticals, Louisville, KY, USA; ALcon, Hünenberg, Switzerland) je C3 inhibitor koji se daje intravitrealnom injekcijom čije djelovanje traje tijekom šest mjeseci. Faza I kliničkog ispitivanja (NCT00473928) dokazala je njegovu sigurnost, a faza II potrebna je da bi dokazala sigurnost i efikasnost primjene kod "suhog" AMD-a ${ }^{70}$.

ARC1905-avacincaptad pegol (Zimura ; Ophthotech Corp., Princeton, NJ, USA) je lijek koji za metu ima C5 komponentu komplementa te je dovršena Faza I istraživanja (NCT00950638) $)^{71}$. U planu je Faza II/III istraživanja ${ }^{11}$.

Eculizumab (Soliris; ; Alexon Pharmaceuticals, Cheshire, CT, USA), još je jedan lijek koji cilja na C5 komponentu komplementa. COMPLETE studija nije pokazala redukciju progresije GA po upotrebi Eculizumaba ${ }^{72}$. 
Lampalizumab (FCFD4514S; Genentech/Roche, San Francisco, CA, USA) je humanizirano monoklonsko antitijelo koje cilja komplement faktor D u alternativnom putu aktivacije komplementa. Faza II kliničkog ispitivanja MAHALO-studija (NCT02288559) prva je studija koja je pokazala usporavanje rasta GA putem inhibicije komplementa $(20.4 \%$ je stopa redukcije zone GA u 18 mjeseci u usporedbi s placebom $)^{73}$. Nažalost, u Fazi III ispitivanja studijama CHROMA (NCT02247479) i SPECTRI (NCT02247531), najvećim dosadašnjim studijama, lampalizumab u dozi od $10 \mathrm{mg}$ intravitrealno svaka četiri ili šest tjedana tijekom 48 tjedana nije reducirao povećanje GA-a u odnosu na placebo, točnije, zabilježeno je povećanje zone GA-a otprilike $2 \mathrm{~mm}^{2}$ godišnje ${ }^{74}$.

Sirolimus (Rapamycin ; MacuSight/Santen, Union City, CA, USA) je makrolidni imunosupresivni lijek s protuupalnom, antiangiogenom i antifibroznom aktivnošću. Dobro se podnosi, ali za sada nije pokazao efikasnost u terapiji „suhog“ AMD-a”7.

Glatiramer acetate (Copaxone; Reva Pharmaceuticals, Kfar-Saba, Israel) proučavan je zbog svog imunomodlatornog efekta preko alteracije diferencijacije T-stanica u tretmanu GA-a. Faza I studije (NCT00541333) pokazuje redukciju područja s druzama kod pacijenata nakon tjednih potkožnih injekcija Glatiramera tijekom 12 tjedana $^{76}$. Faza II/III studije (NCT00466076) je pred završetkom $^{77}$.

RN6G (Pfizer, New York, NY, USA) i GSK933776 (GlaxoSmithKline, Brentford, UK) humanizirana monoklonalna antitijela koja djeluju na amiloidbeta i daju intravenskom injekcijom, odnosno intravenskom infuzijom proučavaju se u fazi II kliničkog ispitivanja (NCT01577381 i NCT01342926), pri čemu su rezultati za RN6G nezadovoljavajući nakon dovršetka studije, a rezultati za GSK933776 još nisu dostupni ${ }^{78,79}$.

\section{Neuroprotektivni lijekovi}

U svrhu neuroprotekcije ispituju se dva lijeka: cilijarni neurotrofički faktor-501 (engl. ciliary neurotrophic factor; CNTF) i Brimonidin.

CNTF član je obitelji IL-6 citokina i pokazuje zaštitno djelovanje prema fotoreceptorima kod animalnih modela ${ }^{80}$. Neurotech Pharmaceuticals (Cumberland, RI, USA) razvio je dobro podnošlji- vu intraokularnu enkapsuliranu staničnu tehnologiju (engl. encapsulated cell technology; ECT) koja u kombinaciji s CNTF-om u sporootpuštajućoj platformi (NT-501) otpušta lijek duže od godinu dana $^{81}$. Faza II randomiziranog, dvostruko slijepog istraživanja (NCT00447954) ispitivala je dvogodišnje rezultate NT-501 implantata kod pacijenata s GA-om i zabilježila obećavajuće rezultate ${ }^{82}$. 51 pacijent dobivao je visoku ili nisku dozu NT-501 implantata ili placebo. Zhang i suradnici pokazali su da stabilizacija vidne oštrine ovisi o primijenje-

Danas su nam dostupne brojne nove dijagnostičke metode koje nam omogućavaju bolje praćenje morfoloških promjena mrežnice, RPE (engl. retinal pigment epithelium) i žilnice, kao i širenja područja atrofije.

noj dozi te je kod pacijenata koji su dobili visoku dozu zabilježen gubitak < 15 slova na ETDRS karti kod $96.3 \%$ pacijenata, a kod onih s niskom dozom kod $83.3 \%$ pacijenata, dok je kod onih $\mathrm{s}$ placebom tako bilo u $75 \%$ pacijenata u 12-mjesečnom ispitivanju ${ }^{83}$. Stabilizacija vidne oštrine povezana je s povećanjem centralne debljine makule zabilježene OCT-om.

Brimonidin (Alphagan ${ }^{\circ}$ ), $\alpha-2$ agonist, koji se koristi za liječenje glaukoma, također pokazuje neuroprotektivni učinak u animalnim modelima ${ }^{84,85}$. Faza II multicentrične, dvostruko slijepe, randomizirane studije (NCT00658619) ispitivala je efikasnost i sigurnost Brimonidina kao intravitrealnog biorazgradljivog implantata (Allergan, Irvine, CA, USA) ${ }^{86}$. Ispitivane su promjene GA područja i BCVA (engl. best corrected visual acuity, najbolja korigirana vidna oštrina) kod 119 pacijenata s bilateralnim GA-om koji su liječeni s 200 ili $400 \mu$ g Brimonidina ili placebom svaka tri mjeseca tijekom razdoblja od 21 mjeseca. Rezultati nisu prikazali pouzdane podatke i zato je u tijeku drugo multicentrično istraživanje (NCT02087085) ${ }^{87}$. Preliminarni rezultati pokazuju da se u 24 mjeseca ispitivanja povećalo GA područje u 311 ispitivanih očiju tretiranih s 400 $\mu \mathrm{g}$ Brimonidina i kod onih s placebom. Dovršetak studije očekuje se u ožujku 2019.

\section{Antioksidanti}

Učinak je opisan ranije u dijelu o dodacima prehrani vezano uz studije AREDS i AREDS2. 
B-karoten, vitamini C i E te cink smanjuju progresiju AMD-a za $25 \%$.

\section{Pojačala koroidalne perfuzije}

Kod starijih pacijenata debljina žilnice je smanjena i zato novi cilj terapije kod „suhog“ AMD-a vodi do mogućnosti pojačanja koroidalnog protoka krvi ${ }^{88}$. Koroidalna cirkulacija ima važnu ulogu u osiguravanju ishrane i odstranjenju otpadnih tvari mrežnice i RPE-a ${ }^{89}$. Tekuća klinička istraživanja s tim ciljem ispituju određene vazodilatatore koji bi mogli pojačati koroidalni protok i usporiti progresiju „suhog“ AMD-a.

Alprostadil (Prostavasin ${ }^{\circledR}$ UCB Pharma, Berkshire, UK) pokazuje se superiornim placebu u fazi III multicentrične kontrolirane randomizirane studije (NCT00619229) kod pacijenata sa „suhim" AMD-om ${ }^{90,91}$. Pacijenti liječeni AlprostadiIom pokazuju BCVA bolji od 0.94 reda $u$ usporedbi s onima tretiranim placebom nakon tri mjeseca, a što se povećava na 1.51 red nakon 6 mjeseci. Preporučene su ipak studije s dužim rokom praćenja, kako bi se ispitaji dugotrajni efekti i sigurnost.

MC-1101, novi vazodilatator ispitan malom pilotstudijom (NCT01922128), pokazuje sigurnost i dobru podnošljivost za topičku upotrebu te povećanje koroidalnog protoka $\mathrm{krvi}^{92}$. Lijek također pokazuje protuupalni i antioksidantni učinak. Sigurnost i efikasnost MC-1101 također ispituje tekuća randomizirana faza II/II istraživanja (NCT02127463) koje uključuje 60 pacijenata s blagom i umjerenom formom „suhog“ AMD-a ${ }^{93}$.

Moxaverine, neselektivni inhibitor fosfodiesteraze pokazuje kontradiktorne rezultate u različitim studijama. Schmidl sa suradnicima izvješćuje da oralna administracija lijeka nije uspješna u pojačanju koroidalnog protoka, dok Resch i Pemp sa suradnicima pokazuju da intravenski primijenjen lijek povećava koroidalni protok u usporedbi s placebom ${ }^{94-96}$. Moguće je da su različiti rezultati uzrokovani načinom primjene, ali su svakako potrebna daljnja istraživanja za utvrđivanje učinkovitosti Moxaverina.

Sildenafil (Viagra*; Pfizer Inc, New York, NY, USA), poznati je vazodilatator čija je uloga u liječenju „suhog“ AMD-a još nejasna. Metelitsina sa suradnicima tvrdi da taj lijek nema učinka u poboljšanju koroidalnog protoka u makuli kod pacijenata $\mathrm{s}$ AMD-om ${ }^{97}$.

\section{Terapija matičnim stanicama}

Liječenje matičnim stanicama predstavlja obećavajući novi pristup u liječenju AMD-a. Budući da dosadašnja istraživanja pokazuju da su RPE i fotoreceptori primarno pogođeni u GA-u, njihova transplantacija čini se kao zanimljiva terapeutska opcija ${ }^{98}$. Trenutno se vrše klinička ispitivanja humanih pluripotentnih matičnih stanica, embrionalnih (hESC, engl. human embryonic stem cell) ili induciranih (iPSC, engl. induced pluripotent stem cell) u liječenju AMD, $a^{99-101}$, no treba naglasiti da terapija matičnim stanicama zahtijeva dugotrajan i multidisciplinaran pristup. Postoji mnogo razloga za i protiv koji moraju biti analizirani u cilju punog razvoja tog novog i atraktivnog pristupa liječenju.

\section{Modulatori lipida}

U nekoliko studija pokazano je da su lipidi sastavni dio druza te da se akumuliraju unutar prostora makule ${ }^{102}$.

Barbosa sa suradnicima pokazuje da je upotreba statina statistički signifikantna u reduciranju pojave AMD-a kod pacijenata sa 68 i više godina ${ }^{103}$, međutim, povezanost uzimanja statina i AMD-a ostaje kontroverzna, kao što pokazuje pregledni članak Cochrane baze podataka 2012, i do danas nije pronađena nijedna studija o GA-u s tim lijekom $^{104}$.

\section{Tretman ispodpražnim laserom}

Određene studije pokazale su mogućnost revitalizacije tkiva mrežnice ispodpražnim laserom, čak i kod dosad neizlječivih bolesti mrežnice, kao što je to retinopatija pigmentosa ${ }^{105}$. Nekoliko je istraživanja u posljednje vrijeme pokazalo mogućnosti ispodpražnog lasera $u$ indukciji regresije određenih fenotipova AMD-a kao što su retikularne pseudodruze (RPD, engl. reticular pseudodrusen), početni GA (nGA, engl. nascent geographic atrophy) i GA udružen s druzama (DAGA, engl. drusen-associated geographic atrophy). U tijeku je faza I-II pilot studije PASCAL-GA koju provode retinolozi bolnice San Raffaele iz Milana. Cilj PASCAL-GA protokola je utvrditi može li ispodpražni laser obnoviti funkciju RPE-a u očima s RPD-om i nGA-om pružajući zaštitu od razvoja proširenog GA-a ${ }^{106}$. 
Na našoj Klinici u Rijeci također koristimo oko godinu dana ispodpražni laser za pokušaj liječenja „suhog“ AMD-a te su prvi kratkoročni rezultati skromni, ali ohrabrujući, i zahtijevaju daljnje tretmane i praćenje. Izvjesno je da konzervativna i kirurška terapija nove generacije, uključujući ispodpražni laser, može imati uspjeha u smanjenju stadija AMD-a.

\section{ZAKLJUČCI}

GA, terminalna forma „suhog“ AMD-a, progresivna je bolest i za sada nema odobrenog lijeka. U tijeku je više studija s ciljem pronalaženja učinkovite terapije koja bi spriječila povećanje područja atrofije i omogućila da pacijenti izbjegnu razvoj teže forme bolesti te očuvaju što bolju vidnu funkciju. Moguće je da će se mnogi od testiranih lijekova pokazati neučinkoviti te će ih samo nekoliko postati dostupni u kliničkoj praksi.

U ovom članku usredotočili smo se na trenutne podatke o mogućim metodama terapije vođeni dosadašnjim saznanjima o čimbenicima koji bi mogli imati ključnu ulogu u razvoju i progresiji „suhog“ AMD-a, ali patogeneza same bolesti još je uvijek nedovoljno jasna. Buduće studije trebat će staviti fokus na razumijevanje svih mehanizama koji su povezani sa „suhim” AMD-om i razviti i druge moguće terapeutske pristupe.

Neki od ovdje spomenutih lijekova pokazali su potencijalnu učinkovitost u preliminarnim rezultatima i moguće je da će stvarno biti pogodni za liječenje "suhog" AMD-a te se ranije pojaviti na tržištu. Najvažnije je, međutim, dokazati efikasnost i sigurnost lijeka dugotrajnim praćenjem. Tek nakon toga moći ćemo terapiju ponuditi našim pacijentima kako bi očuvali svoju vidnu funkciju.

Izjava o sukobu interesa: autori izjavljuju da ne postoji sukob interesa.

\section{LITERATURA}

1. Klein R, Klein BE, Lee KE, Cruickshanks KJ, Gangnon RE. Changes in visual acuity in a population over a 15-year period: the Beaver Dam Eye Study. Am J Ophthalmol 2006;142:539-49.

2. Lim LS, Mitchell P, Seddon JM, Holz FG, Wong TJ. Age-related macular degeneration. Lancet 2012;379:1728-38.

3. Age-Related Eye Disease Study Research Group. A randomized, placebo-controlled, clinical trial of high-dose supplementation with vitamins $\mathrm{C}$ and $\mathrm{E}$, beta carotene, and zinc for age-related macular degeneration and vision loss: AREDS report no. 8. Arch Ophthalmol 2001; 119:1417-36.

4. Rudnicka AR, Jarrar Z, Wormald R, Cook DG, Fletcher A, Owen CG. Age and gender variations in age-related macular degeneration prevalence in populations of European ancestry: a meta-analysis. Ophtalmology 2012;119:571-80.

5. Bird AC, Bressler NM, Bressler SB, Chisholm IH, Coskas $G$, Davis MD et al. An International Classification and Grading System for Age-Related Macular Maculopathy and Age-Related Macular Degeneration. The International ARM Epidemiology Study Group. Surv Ophtalmol 1995;39:367-74.

6. Couch SM, Bakri SJ. Review of combination therapies for neovascular age-related macular degeneration. Semin Ophthalmol 2011;26:114-20.

7. Lally DR, Gerstenblith AT, Regillo CD. Preferred therapies for neovascular age-related macular degeneration. Curr Opin Ophthalmol 2012;23:182-8.

8. Schlottmann PG, Alezzandrini AA, Zas M, Rodriguez FJ, Luna JD, Wu L. New treatment modalities for neovascular Age-Related Macular Degeneration. Asia Pac J Ophtalmol (Phila) 2017;6:514-9.

9. Yerramothu P. New Therapies of Neovascular AMDBeyond Anti-VEGFs. Vision 2018;2:31.

10. Holz FG, Strauss EC, Schmitz-Valckenberg S, van Lookeren Campagne M. Geographic Atrophy: Clinical Features and Potential Therapeutic Approaches. Ophtalmology 2014;121:1079-91.

11. Hanus J, Zhao F, Wang S. Current Therapeutic Development in Atrophic Age-Related Macular Degeneration. Br J Ophtalmol 2016;100:122-7.

12. Sadda SR, Chakravarthy U, Birch DG, Staurenghi G, Henry EC, Brittain C. Clinical endpoints for the study of geographic atrophy secondary to age-related macular degeneration. Retina 2016;36:1806-22.

13. Clemons $T E$, Milton RC, Klein R, Seddon JM, Ferris FL 3rd; Age-Related Eye Disease Study Research Group. Risk factors for the incidence of Advanced Age-Related Macular Degeneration in the Age-Related Eye Disease Study (AREDS) AREDS report no. 19. Ophthalmology 2005;112:533-9.

14. Ferris FL III, Wilkinson CP, Bird A, Chakravarthy U, Chew $\mathrm{E}, \mathrm{Csaky} \mathrm{K}$ et al. Clinical classification of age-related macular degeneration. Ophthalmology 2013;120:844-51.

15. Gass JD. Drusen and disciform macular detachment and degeneration. Arch Ophthalmol1973;90:206-17.

16. Buch $H$, Nielsen NV, Vinding $T$, Jensen GB, Prause JU, la Cour M. 14-year incidence progression and visual morbidity of age-related maculopaty: The Copenhagen City Eye Study. Ophthalmology 2005;112:787-98.

17. Rudnicka AR, Kapetanakis VV, Jarrar Z, Wathern AK, Wormald $R$, Fletcher $A E$ et al. Incidence of late-stage age-related macular degeneration in American whites: systematic review and meta-analysis. Am J Ophthalmol 2015;160:85-93.e3.

18. Klein R, Klein BE, Knudtson MD, Meuer SM, Swift M, Gangnon RE. Fifteen-year cumulative incidence of agerelated macular degeneration: the Beaver Dam Eye Study. Ophthalmology 2007;114:253-62.

19. Smith W, Assink J, Klein R, Mitchell P, Klaver CC, Klein BE et al. Risk factors for age-related macular degeneration: 
Pooled findings from three continents. Ophthalmology 2001;108:697-704.

20. Fraser-Bell S, Wu J, Klein R, Azen SP, Varma R. Smoking, Alcohol Intake, Estrogen Use, and Age-related Macular Degeneration in Latinos: The Los Angeles Latino Eye Study. Am J Ophthalmol 2006;141:79-87.

21. Age-Related Eye Disease Study Research Group. Risk factors associated with age-related macular degeneration. A case-control study in the age-related eye disease study: Age-Related Eye Disease Study Report Number 3. Ophthalmology 2000;107:2224-32.

22. Klein R, Klein BE, Tomany SC, Cruickshanks KJ. The Association of Cardiovascular Disease with the Long-term Incidence of Age-Related Maculopathy: The Beaver Dam Eye Study. Ophthalmology 2003;110:1273-80.

23. Postel EA, Agarwal A, Caldwell J, Gallins P, Toth C, Schmidt $\mathrm{S}$ et al. Complement Factor $\mathrm{H}$ Increases Risk for Atrophic Age-Related Macular Degeneration. Ophthalmology 2006;113:1504-7.

24. Despriet DD, van Duijn CM, Oostra BA, Uitterlinden AG, Hofman A, Wright AF et al. Complement Component C3 and Risk of Age-Related Macular Degeneration. Ophthalmology 2009;116:474-80.e2.

25. Cameron DJ, Yang Z, Gibbs D, Chen H, Kaminoh Y, Jorgensen $A$ et al. HTRA1 variant confers similar risk to $\mathrm{Ge}$ ographic Atrophy and Neovascular Age-Related Macular Degeneration. Cell Cycle 2007;6:1122-5.

26. Seddon JM, Ajani UA, Mitchell BD. Familial aggregation of age-related maculopathy. Am J Ophthalmol 1997; 123:199-206.

27. Davis MD, Gangnon RE, Lee LY, Hubbard LD, Klein BE, Klein $R$ et al. The Age-Related Eye Disease Study Severity Scale for Age-Related Macular Degeneration: AREDS report No. 17. Arch Ophthalmol 2005;123:1484-98.

28. Klein ML, Ferris FL III, Armstrong J, Hwang TS, Chew EY, Bressler SB et al. Retinal Precursors and the Development of Geographic Atrophy in Age-Related Macular Degeneration. Ophthalmology 2008;115:1026-31.

29. Pauleikhoff D, Spital G, Radermacher M, Brumm GA, Lommatzsch A, Bird AC. A Fluorescein and Indocyanine Green Angiographic Study of Choriocapillaris in Age-related Macular Disease. Arch Ophthalmol 1999;117:1353-8.

30. Kashani AH. Stem Cell Therapy in Nonneovascular AgeRelated Macular Degeneration. Invest Ophthalmol Vis Sci 2016;57:ORSFm1-9.

31. Casswell AG, Kohen D, Bird AC. Retinal pigment epithelial detachments in the elderly: classification and outcome. Br J Ophthalmol 1985;69:397-403.

32. Marsiglia M, Boddu S, Bearelly S, Xu L, Breaux BE Jr, Freund $\mathrm{KB}$ et al. Association between geographic atrophy progression and reticular pseudodrusen in eyes with dry age-related macular degeneration. Invest Ophthalmol Vis Sci 2013;54:7362-9.

33. Lutty G, Grunwald J, Majji AB, Uyama M, Yoneya S. Changes in choriocapillaris and retinal pigment epithelium in age-related macular degeneration. Mol Vis 1999; 5:35.

34. McLeod DS, Taomoto M, Otsuji T, Green WR, Sunness Js, LuttyGA. Quantifying Changes in RPE and Choroidal Vasculature in Eyes with Age-Related Macular Degeneration. Invest Ophthalmol Vis Sci 2002;43:1986-93.

35. Sparrow JR, Boulton M. RPE lipofuscin and its role in retinal pathobiology. Exp Eye Res 2005;80:595-606.
36. Curcio CA, Medeiros NE, Milican CL. Photoreceptor Loss in Age-Related Macular Degeneration. Invest Ophthalmol Vis Sci 1996;37:1236-49.

37. Kim SY, Sadda S, Humayun MS, de Juan E Jr, Melia BM, Green WR. Morphometric Analysis of the Macula in Eyes With Geographic Atrophy due to Age-Related Macular Degeneration. Retina 2002;22:464-70.

38. Holz FG, Schutt F, Kopitz J, Eldred GE, Kruse FE, Völcker $\mathrm{HE}$ et al. Inhibition of Lysosomal Degradative Functions in RPE Cells by a Retinoid Component of Lipofuscin. Invest Ophthalmol Vis Sci 1999;40:737-43.

39. Beatty S, Koh H, Phil M, Henson D, Boulton M. The Role of Oxidative Stress in the Pathogenesis of Age-Related Macular Degeneration. Surv Ophthalmol 2000;45:115-34.

40. Rózanowska M, Korytowski W, Rózanowski B, Skumatz C, Boulton M, Burke JM et al. Photoreactivity of Aged Human RPE Melanosomes: A Comparison with Lipofuscin. Invest Ophthalmol Vis Sci 2002;43:2088-96.

41. Anderson DH, Mullins RF, Hageman GS, Johnson LV. A Role for Local Inflammation in the Formation of Drusen in the Aging Eye. Am J Ophthalmol 2002;134:411-31.

42. Brader HS, Ying GS, Martin ER, Maguire MG; Complications of Age-Related Macular Degeneration Prevention Trial-CAPT Research Group. New grading criteria allow for earlier detection of geographic atrophy in clinical trials. Invest Ophthalmol Vis Sci 2011;52:9218-25.

43. Holz FG, Bellman C, Staudt S, Schütt F, Völcker HE. Fundus autofluorescence and development of geographic atrophy in age-related macular degeneration. Invest Ophthalmol Vis Sci 2001;42:1051-6.

44. Schuman SG, Koreishi AF, Farsiu S, JungSH, Izatt JA, Toth CA. Photoreceptor layer thinning over drusen in eyes with age-related macular degeneration imaged in vivo with spectral-domain optical coherence tomography. Ophthalmology 2009;116:488-496.e2.

45. Leuschen JN, Schuman SG, Winter KP, McCall MN, Wong WT, Chew EY et al. Spectral-domain optical coherence tomography characteristics of intermediate agerelated macular degeneration. Ophthalmology 2013; 120:140-50.

46. Christenbury JG, Folgar FA, O'Connell RV, Chiu SJ, Farsiu $\mathrm{S}$, Toth CA et al. Progression of intermediate age-related macular degeneration with proliferation and inner retinal migration of hyperreflective foci. Ophthalmology 2013;120:1038-45.

47. Yehoshua Z, Rosenfeld PJ, Gregori G, Feuer WJ, Falcão $\mathrm{M}$, Lujan BJ et al. Progression of geographic atrophy in age-related macular degeneration imaged with spectral domain optical coherence tomography. Ophthalmology 2011;118:679-86.

48. Shuman JS, Puliafito CA, Fujimoto JG. Optical Coherence Tomography of Ocular Diseases. $2^{\text {nd }}$ Edition. New Jersey: Slack Incorporated, 2004;235-67.

49. Bearelly S, Chau FY, Koreishi A, Stinnett SS, Izatt JA, Toth CA. Spectral Domain Coherence Tomography Imaging of Geographic Atrophy Margins. Ophthalmology 2009; 116:1762-9.

50. Csaky KG. What Should We Be Measuring as a Geographic Atrophy Endpoint? Abstracts at Annual Meeting of the American Academy of Ophtalmology, Subspeciality Day Retina Sillabus. Las Vegas, 2015;154-6.

51. Wu Z, Luu CD, Ayton LN, Goh JK, Lucci LM, Hubbard WC et al. Optical coherence tomography-defined changes 
preceding the development of drusen-associated atrophy in age-related macular degeneration. Ophthalmology 2014;121:2415-22.

52. Ouyang $Y$, Heussen FM, Hariri A, Keane PA, Sadda SR. Optical coherence tomography-based observation of the natural history of drusenoid lesion in eyes with dry age-related macular degeneration. Ophthalmology 2013;120:2656-65.

53. Von Ruckmann A, Fitzke FW, Bird AC. Fundus Autofluorescence in Age-Related Macular Disease Imaged with Laser scanning Ophthalmoscope. Invest Ophthalmol Vis Sci 1997;38:478-86.

54. Schmitz-Valkenberg S, Bültmann S, Dreyhaupt J, Bindewald A, Holz FG, Rohrschneider K. Fundus autofluorescence and fundus perimetry in the junctional zone of geographic atrophy in patients with age-related macular degeneration. Invest Ophthalmol Vis Sci 2004;45: 4470-6.

55. Bindewald A, Schmitz-Valckenberg S, Jorzik JJ, Dolar-Szczasny J, Sieber $\mathrm{H}$, Keilhauer $\mathrm{C}$ et al. Classification of abnormal fundus autofluorescence patterns in the junctional zone of geographic atrophy in patients with age related macular degeneration. Br J Ophthalmol 2005;89:874-8.

56. Holz FG, Bindewald-Wittich A, Fleckenstein M, Dreyhaupt J, Scholl HP, Schmitz-Valckenberg S et al. Progression of geographic atrophy and impact of fundus autofluorescence patterns in age-related macular degeneration. Am J Ophthalmol 2007;143:463-72.

57. Moult EM, Waheed NK, Novais EA, Choi W, Lee B, Ploner SB et al. Swept-source optical coherence tomography angiography reveals choriocapillaris alterations in eyes with nascent geographic atrophy and drusen-associated geographic atrophy. Retina 2016;36Suppl 1:2-11.

58. Toto L, Borrelli E, Mastropasqua R, Di Antonio L, Doronzo $E$, Carpineto $P$ et al. Association between outer retinal alterations and microvascular changes in intermediate stage age-related macular degeneration: an optical coherence tomography angiography study. $\mathrm{Br}$ J Ophthalmol 2017;101:774-9.

59. Omenn GS, Goodman GE, Thornquist MD, Balmes J, CuIlen MR, Glass A et al. Risk factors for lung cancer and for intervention effects in CARET, the Beta-Carotene and Retinol Efficacy Trial. J Natl Cancer Inst 1996;88: 1550-9.

60. Age-Related Eye Disease Study 2 Research Group. Lutein + zeaxanthin and omega-3 fatty acids for age-related macular degeneration: the Age-Related Eye Disease Study 2 (AREDS2) randomized clinical trial. JAMA 2013; 309:2005-15.

61. Ho E, Beaver LM, Williams DE, Dashwood RH. Dietary factors and epigenetic regulation for prostate cancer prevention. Adv Nutr 2011;2:497-510.

62. Brunk UT, Terman A. Lipofuscin: mechanisms of age-related accumulation and influence on cell function. Free Radic Biol Med 2002;33:611-9.

63. Mata NL, Lichter JB, Vogel R, Han Y, Bui TV, Singerman $\mathrm{LJ}$. Investigation of oral fenretinide for treatment of geographic atrophy in age-related macular degeneration. Retina 2013;33:498-507.

64. Acucela Inc: Study of the Safety, Tolerability, Pharmacokinetics and Pharmacodynamics of ACU-4429 in Subjects With Geographic Atrophy [Internet]. In: ClinicalTrials.gov [cited 2018 Apr 30]. Available from: https://clinicaltrials.gov/ct2/show/NCT01002950.
65. Acucela Inc: Safety and Efficacy Assessment Treatment Trials of Emixustat Hydrochloride (SEATTLE) [Internet]. In: ClinicalTrials.gov [cited 2018 Apr 30]. Available from: https://clinicaltrials.gov/ct2/show/NCT01802866.

66. Gehrs KM, Jackson JR, Brown EN, Allikmets R, Hageman GS. Complement, age-related macular degeneration and a vision of the future. Arch Ophthalmol 2010;128: 349-58.

67. Alimera Sciences: Fluocinolone Acetonide Intravitreal Inserts in Geographic Atrophy [Internet]. In: ClinicalTrials.gov [cited 2018 Apr 30]. Available from: https://clinicaltrials.gov/ct2/show/NCT00695318.

68. Haines JL, Hauser MA, Schmidt S, Scott WK, Olson LM, Gallins $\mathrm{P}$ et al. Complement factor $\mathrm{H}$ variant increases the risk of age-related macular degeneration. Science 2005;308:419-21.

69. Yates JR, Sepp T, Matharu BK, Khan JC, Thurlby DA, Shahid $\mathrm{H}$ et al. Complement $\mathrm{C} 3$ variant and the risk of agerelated macular degeneration. N Engl J Med 2007;357: 553-61.

70. Potentia Pharmaceuticals, Inc: Safety of Intravitreal POT-4 Therapy for Patients With Neovascular Age-Related Macular Degeneration (AMD) (AsaP) [Internet]. In: ClinicalTrials.gov [cited 2018 Apr 30]. Available from: https://clinicaltrials.gov/ct2/show/NCT00473928.

71. Ophthotech Corporation: A Study of ARC1905 (Anti-C5 Aptamer) in Subjects With Dry Age-related Macular Degeneration [Internet]. In: ClinicalTrials.gov [cited 2018 Apr 30]. Available from: https://clinicaltrials.gov/ct2/ show/NCT00950638

72. Yehoshua Z, de Amorim Garcia Filho CA, Nunes RP, Gregori G, Penha FM, Moshfeghi AA et al. Systemic complement inhibition with eculizumab for geographic atrophy in age-related macular degeneration: the COMPLETE study. Ophthalmology 2014;121:693-701.

73. Genentech, Inc: A Study of Lampalizumab Intravitreal Injections Administered Every Two Weeks or Every Four Weeks to Participants With Geographic Atrophy [Internet]. In: ClinicalTrials.gov [cited 2018 Apr 30]. Available from: https://clinicaltrials.gov/ct2/show/NCT02288559.

74. Holz FG, Sadda SR, Busbee B, Chew EY, Mitchell P, Tufail A et al. Efficacy and Safety of Lampalizumab for Geographic Atrophy Due to Age-Related Macular Degeneration: Chroma and Spectri Phase 3 Randomized Clinical Trials. JAMA Ophtalmol 2018;136:666-77.

75. Wong WT, Dresner S, Forooghian F, Glaser T, Doss L, Zhou $\mathrm{M}$ et al. Treatment of geographic atrophy with subconjunctival sirolimus: results of a phase $1 /$ II clinical trial. Invest Ophthalmol Vis Sci 2013;54:2941-50.

76. Landa G, Butovsky O, Shoshani J, Schwartz M, Pollack A. Weekly vaccination with Copaxone (glatiramer acetate) as a potential therapy for dry age-related macular degeneration.Curr Eye Res 2008;33:1011-3.

77. Kaplan Medical Center: Copaxone in Age Related Macular Degeneration [Internet]. In: ClinicalTrials.gov [cited 2018 Apr 30]. Available from: https://clinicaltrials. gov/ct2/show/NCT00466076.

78. Pfizer: Efficacy, Safety And Tolerability Study Of RN6G In Subjects With Geographic Atrophy Secondary to Agerelated Macular Degeneration [Internet]. In: ClinicalTrials.gov [cited 2018 Apr 30]. Available from: https:// clinicaltrials.gov/ct2/show/NCT01577381.

79. GlaxoSmithKline: Clinical Study to Investigate Safety and Efficacy of GSK933776 in Adult Patients With Geo- 
graphic Atrophy Secondary to Age-related Macular Degeneration[Internet]. In: ClinicalTrials.gov [cited 2018 Apr 30]. Available from: https://clinicaltrials.gov/ ct2/show/NCT01342926.

80. Tao W, Wen R, Goddard MB, Sherman SD, O'Rourke PJ, Stabila PF et al. Encapsulated cell-based delivery of CNTF reduces photoreceptor degeneration in animal models of retinitis pigmentosa. Invest Ophthalmol Vis Sci 2002;43:3292-8.

81. Kauper K, McGovern C, Sherman S, Heatherton P, Rapoza R, Stabila P et al. Two-year intraocular delivery of ciliary neurotrophic factor by encapsulated cell technology implants in patients with chronic retinal degenerative diseases. Invest Ophthalmol Vis Sci 2012;53:7484-91.

82. Neurotech Pharmaceuticals: A Study of an Encapsulated Cell Technology (ECT) Implant for Patients With Atrophic Macular Degeneration [Internet]. In: ClinicalTrials.gov [cited 2018 Apr 30]. Available from: https:// clinicaltrials.gov/ct2/show/NCT00447954.

83. Zhang K, Hopkins JJ, Heier JS, Birch DG, Halperin LS, Albini TA et al. Ciliary neurotrophic factor delivered by encapsulated cell intraocular implants for treatment of geographic atrophy in age-related macular degeneration. Proc Natl Acad Sci U S A 2011;108:6241-5.

84. WoldeMussie E, Ruiz G, Wijono M, Wheeler LA. Neuroprotection of retinal ganglion cells by brimonidine in rats with laser-induced chronic ocular hypertension. Invest Ophthalmol Vis Sci 2001;42:2849-55.

85. Wheeler L, WoldeMussie E, Lai R. Role of alpha-2 agonists in neuroprotection. Surv Ophthalmol 2003;48 Suppl 1:S47-51.

86. Allergan: Safety and Efficacy of Brimonidine Intravitreal Implant in Patients With Geographic Atrophy Due to Age-related Macular Degeneration (AMD) [Internet]. In: ClinicalTrials.gov [cited 2018 Apr 30]. Available from: https://clinicaltrials.gov/ct2/show/NCT00658619.

87. Allergan: A Safety and Efficacy Study of Brimonidine Intravitreal Implant in Geographic Atrophy Secondary to Age-related Macular Degeneration (BEACON) [Internet]. In: ClinicalTrials.gov [cited 2018 Apr 30]. Available from: https://clinicaltrials.gov/ct2/show/NCT02087085.

88. Grunwald JE, Metelitsina TI, Dupont JC, Ying GS, Maguire MG. Reduced foveolar choroidal blood flow in eyes with increasing AMD severity. Invest Ophthalmol Vis Sci 2005;46:1033-8.

89. Booij JC, Baas DC, Beisekeeva J, Gorgels TG, Bergen AA. The dynamic nature of Bruch's membrane. Prog Retin Eye Res 2010;29:1-18.

90. UCB Pharma: Alprostadil in Maculopathy Study (AIMS) [Internet]. In: ClinicalTrials.gov [cited 2018 Apr 30]. Available from: https://clinicaltrials.gov/ct2/show/NCT03252626.

91. Augustin AJ, Diehm C, Grieger F, Bentz J. Alprostadil infusion in patients with dry age related macular degeneration: a randomized controlled clinical trial. Expert Opin Investig Drugs 2013;22:803-12.

92. MacuCLEAR, Inc: Safety Study of a Topical Treatment for Dry Age Related Macular Degeneration [Internet]. In: ClinicalTrials.gov [cited 2018 Jan 24]. Available from: https://clinicaltrials.gov/ct2/show/NCT01601483.
93. MacuCLEAR, Inc: Phase II/III Study of the Efficacy and Safety of MacuCLEAR MC-1101 in Treating DryAge-Related Macular Degeneration (McCP2/3) [Internet]. In: ClinicalTrials.gov [cited 2018 Jan 24]. Available from: https://clinicaltrials.gov/ct2/show/NCT02127463.

94. Schmidl D, Pemp B, Lasta M, Boltz A, Kaya S, Palkovits S et al. Effects of orally administered moxaverine on ocular blood flow in healthy subjects. Graefes Arch Clin Exp Ophthalmol 2013;251:515-20.

95. Resch H, Weigert G, Karl K, Pemp B, Garhofer G, Schmetterer L.Effect of systemic moxaverine on ocular blood flow in humans. Acta Ophthalmol 2009;87: 731-5.

96. Pemp B, Garhofer G, Lasta M, Schmidl D, Woltz M, Schmetterer $L$. The effects of moxaverine on ocular blood flow in patients with age-related macular degeneration or primary open angle glaucoma and in healthy control subjects. Acta Ophthalmol 2012;90:139-45.

97. Metelitsina TI, Grunwald JE, DuPont JC, Ying GS. Effect of Viagra on the foveolar choroidal circulation of AMD patients. Exp Eye Res 2005;81:159-64.

98. Bhutto I, Lutty G. Understanding age-related macular degeneration (AMD): relationships between the photoreceptor/retinal pigment epithelium/Bruch's membrane/choriocapillaris complex. Mol Aspects Med 2012;33: 295-317.

99. Carr AJ, Vugler AA, Hikita ST, Lawrence JM, Gias C, Chen $\mathrm{LL}$ et al. Protective effects of human iPS-derived retinal pigment epithelium cell transplantation in the retinal dystrophic rat. PLoS One 2009;4:e8152.

100. Cho MS, Kim SJ, Ku SY, Park JH, Lee H, Yoo DH et al. Generation of retinal pigment epithelial cells from human embryonic stem cell-derived spherical neural masses. Stem Cell Res 2012;9:101-9.

101. Buchholz DE, Hikita ST, Rowland TJ, Friedrich AM, Hinman $C R$, Johnson $L V$ et al. Derivation of functional retinal pigmented epithelium from induced pluripotent stem cells. Stem Cells 2009;27:2427-34.

102. Buschini E, Fea AM, Lavia CA, Nassisi M, Pignata G, Zola $M$ et al. Recent developments in the management of dry age-related macular degeneration. Clin Ophthalmol 2015;9:563-74

103. Barbosa DT, Mendes TS, Cíntron-Colon HR, Wang SY, Bhisitkul RB, Singh $\mathrm{K}$ et al. Age-related macular degeneration and protective effect of HMG Co-A reductase inhibitors (statins): results from the National Health and Nutrition Examination Survey 2005-2008. Eye (Lond) 2014;28:472-80.

104. Gehlbach P, Li T, Hatef E. Statins for age-related macular degeneration. Cochrane Database Syst Rev 2012:CD006927.

105. Luttrull JK. Improved retinal and visual function following panmacular subthreshold diode micropulse laser for retinitis pigmentosa. Eye (Lond) 2018;32:1099-110.

106. Querques G, Cicinelli MV, Rabiolo A, de Vitis L, Sacconi $R$, Querques $L$ et al. Laser photocoagulation as treatment of non-exudative age-relatedmacular degeneration: state-of-the-art and future perspectives. Graefes Arch Clin Exp Ophthalmol 2018;256:1-9. 